\title{
The Standard of Location and Visualization of Geo- objects on Thematic Layers of the Geographic Information System
}

\author{
Tatiana Mikheeva \\ Institute of aviation technology \\ Samara University \\ Samara, Russia \\ mikheevati@gmail.com
}

\author{
Vladislav Elizarov \\ Institute of informatics, mathematics \\ and electronics \\ Samara University \\ Samara, Russia \\ elizarov43@gmail.com
}

\author{
Sergey Mikheev \\ Institute of aviation technology \\ Samara University \\ Samara, Russia \\ ms140-500@yandex.ru
}

\begin{abstract}
Currently, the standardization of the thematic layers of the intelligent transport geographic information system is considered to work in a market economy in accordance with the rules of work and the norms of international standardization. Standardization is regarded as an information management tool that provides visualization and location of geo-objects with access to a database. Today it is not enough to strictly follow the requirements of progressive standards - it is necessary to back up the issue of the standard and the provision of services with a safety or quality certificate. The standard of thematic layers in the geographic information system is necessary in terms of streamlining the exchange of data. Developed uniform requirements for the classification and coding of geo-objects on thematic layers and are dictated by the objectives of ensuring the comparability of cartographic information, the unification of forms of its presentation and processing. Conditions have been created for the organization and replenishment of the information database of geo-objects on thematic layers of the intellectual transport geographic information system "ITSGIS".
\end{abstract}

Keywords-intelligent transport geographic information system, ITSGIS, standard, geo-object, layer

\section{INTRODUCTION}

Abroad already in the early 1980s. concluded that the success of a business is determined primarily by the quality of products and services. $80 \%$ of the surveyed 200 large US firms surveyed said that quality is the main factor in the sale of goods at a bargain price. Hence the conclusion: mastering quality assurance methods based on the triad standardization, metrology, certification, is one of the main conditions for a supplier to enter the market with competitive products (services), and hence commercial success.

Thus, the standardization of thematic layers on electronic maps is a tool to ensure not only competitiveness, but also an effective partnership of the manufacturer, customer and seller at all levels of management.

Today it is not enough to strictly follow the requirements of progressive standards - it is necessary to back up the issue of the standard and the provision of services with a safety or quality certificate. The greatest trust among customers and consumers is caused by a certificate for the quality system. It creates confidence in the stability of quality, in the reliability and accuracy of the measured quality indicators, indicating a high culture of production processes and the provision of services $[1,2]$.

In recent years, confirmation of compliance for a number of products with the established requirements has been carried out not only through certification, but also by the manufacturer of the electronic card or the service provider, i.e. first side. Under these conditions, the role and responsibility of the heads of organizations in the competent application by staff of the rules of standardization, metrology and certification increase. Compliance with the rules of metrology allows you to minimize material losses from unreliable measurement results.

There is an urgent need to harmonize domestic rules of standardization, metrology and certification with international rules, since this is an important condition for Russia's accession to the World Trade Organization (WTO) and the country's future activities within this organization. The problem of harmonization is currently being solved primarily through the adoption of laws in the field of technical legislation. December 27, 2002. President of the Russian Federation V.V. Putin signed the Federal Law adopted by the State Duma of December 27, 2002 No. 184the federal law "On Technical Regulation". The Act entered into force on July 1, 2003. Its adoption marked the beginning of the reorganization of the system of standardization and certification, which is necessary for Russia's accession to the WTO and the elimination of technical barriers to trade $[7,8]$.

The standard of thematic layers in the geographic information system is necessary in terms of streamlining the exchange of data. Developed uniform requirements for the classification and coding of geo-objects on thematic layers and are dictated by the objectives of ensuring the comparability of cartographic information, the unification of forms of its presentation and processing. Conditions have been created for the organization and replenishment of the information database of geo-objects on thematic layers of the intellectual transport geographic information system "ITSGIS".

Conditions for the development and improvement of standardization of geo-objects on thematic layers are created. The standard serves the end user as a criterion of judgment, a measure of quality, a certain guarantee of compatibility and interchangeability, thereby contributing to the improvement 
of the quality of work with thematic layers on electronic maps.

Standardization of thematic layers on an electronic map is based on the latest achievements of science in the development of geographic information systems and technologies, techniques for collecting and processing information about geographical objects and practical experience in creating electronic maps with visualization and location of geo-objects on thematic layers of an electronic map. Standardization determines the solution: optimal economic, road safety, increase the capacity of the transport network, many national economic and industry problems. The introduction of scientific achievements into practical activity is accelerated by combining functional and applied areas of science, contributing to the enhancement of their purposefulness in the classification of standardization $[3,4]$.

The purpose of the standardization of intellectual transport geographic information system "ITSGIS" was the classification of the most qualitative, technological and optimal economical variant of visualization and dislocation of geo-objects on thematic layers of the electronic map in the ITSGIS environment. The found options make it possible to achieve optimal ordering, nominal, structure, coloring and visualization of geo-objects in certain layers of the electronic map, taking into account the developed standard. In order to turn this opportunity into reality, it is necessary that the options found become the property of a larger number of electronic maps (federal districts, regions, cities, municipal districts, villages). Only with the universal and repeated use of this solution of existing and potential problems is the logical and semantic effect of the conducted ordering possible.

\section{THEMATIC LAYERS}

All information on an electronic map in the environment of intellectual transport geographic information system "ITSGIS" consists of thematic layers, on which homogeneous graphic information is presented, combined according to some common semantic feature. Mixing on a layer of primitives of different types (classes) is usually not allowed (Fig. 1).

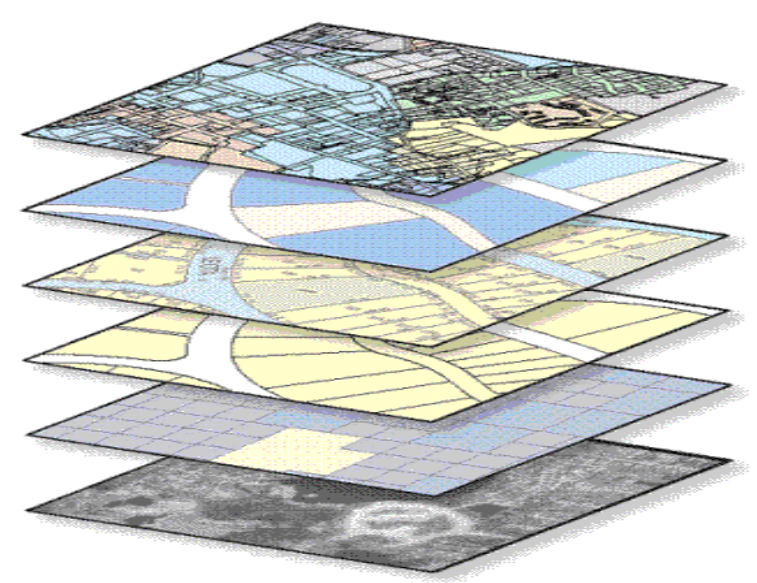

Fig. 1. Layers of geographic information system
Thematic layer in ITSGIS is a set of spatial geo-objects of the same type, belonging to the same class of objects within a certain territory and in the coordinate system common to a set of layers.

\section{GEO-OBJECTS}

Geo-objects are objects of the real geosystem ITSGIS, described by one or several geometric vector primitives, as well as a set of attributes. Geometric vector primitives include points, lines, and polygons. Physically, primitives are described by a sequence of pairs of coordinates of their nodes. Attributes are the numeric or symbolic characteristics of an object, or vector primitive, stored in a special database (DB). Raster images, audio and video materials, as well as behavioral attributes in the form of functions and software modules that are executed under certain conditions are used as attributes.

The set of primitives and attributes forms a simple geo object ITSGIS. A set of simple objects forms a composite geoobject. The hierarchical representation of objects has a number of undoubted advantages: visibility, avoiding duplication of information, support for the principle of inheritance. In this case, ITSGIS is an object-oriented system.

All geo-objects and primitives have their own unique identifier, with the help of which thematic is attached to spatial information.

There are four main types of features: point (points), linear (lines), polygon or polygonal, contour (polygons) and surfaces (reliefs), 0-, 1-, 2- and three-dimensional, respectively, as well as bodies. Points, lines and polygons combine the concept of flat, or planimetric objects, surfaces (as well as bodies) refer to the type of three-dimensional objects, or three-dimensional objects. Collections of simple features can be combined into a composite feature. A complete set of objects of the same class within a given territory forms a layer.

A point geoobject is a 0-dimensional spatial object characterized by coordinates $(\mathrm{X}, \mathrm{Y})$ and attributes associated with it. The collection of point objects forms a point layer $[5,6]$.

A point can be represented by single objects, the length of which does not matter (road sign, traffic light, support), as well as abstract objects that do not have dimensions, but which need to be linked to the territory (node of the traffic network graph, traffic light object).

A linear geo object is a one-dimensional object formed by a sequence of at least 2 points with known coordinates. Each such object can have its own style of lines of a given color, thickness and type. A collection of linear objects form a linear layer.

A contour object (contour, polygon) is a 2-dimensional (areal) object, or an internal region formed by a closed sequence of arcs (in vector-topological representations), identified by an internal point (centroid) and associated attribute values. Each such object is displayed in the form of a closed line of a given color, thickness and style. Such objects are convenient to describe the contours of buildings, areal areas of the territory (part of the transport network). 
The combination of contour objects forms a contour layer $[9,10,11]$.

All geo-objects and primitives have their own unique identifier, with the help of which thematic is attached to spatial information.

There are four main types of features: point (points), linear (lines), polygon or polygonal, contour (polygons) and surfaces (reliefs), 0-, 1-, 2- and three-dimensional, respectively, as well as bodies. Points, lines and polygons combine the concept of flat, or planimetric objects, surfaces (as well as bodies) refer to the type of three-dimensional objects, or three-dimensional objects. Collections of simple features can be combined into a composite feature. A complete set of objects of the same class within a given territory forms a layer. A point geoobject is a 0 -dimensional spatial object characterized by coordinates (X, Y) and attributes associated with it. The collection of point objects forms a point layer.

A point can be represented by single objects, the length of which does not matter (road sign, traffic light, support), as well as abstract objects that do not have dimensions, but which need to be linked to the territory (node of the traffic network graph, traffic light object) [12].
A linear geo object is a one-dimensional object formed by a sequence of at least 2 points with known coordinates. Each such object can have its own style of lines of a given color, thickness and type. A collection of linear objects form a linear layer.

A contour object (contour, polygon) is a 2-dimensional (areal) object, or an internal region formed by a closed sequence of arcs (in vector-topological representations), identified by an internal point (centroid) and associated attribute values. Each such object is displayed in the form of a closed line of a given color, thickness and style. Such objects are convenient to describe the contours of buildings, areal areas of the territory (part of the transport network). The combination of contour objects forms a contour layer [13].

\section{THEMATIC LAYERS}

The development of the ITSGIS standard is based on standardization methods. The method of ordering geoobjects involves managing the variety associated with the reduction of diversity.

As a result of streamlining, lists of final finished products were developed: interfaces and functionality of ITSGIS plugins; albums of typical pictograms of geo-objects; typical forms of technical documents: summary statements of objects of urban and transport infrastructures.

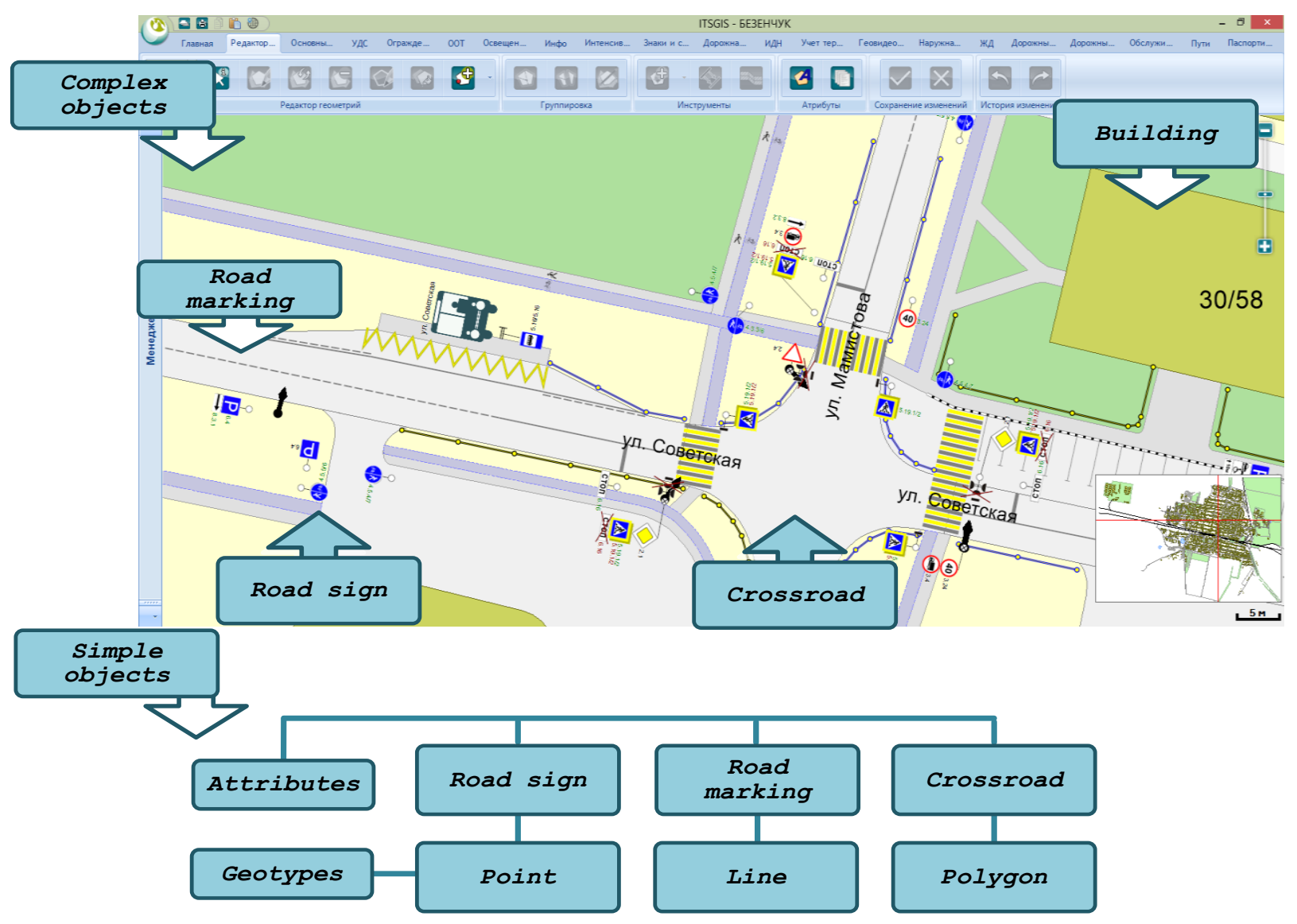

Fig. 2. Types of geo objects on an electronic map 
The ordering method includes the processes of systematization, selection, simplification, typification and optimization.

- Systematization of geoobjects is made on the basis of the principles of consistent classification and ranking of a set of specific geoobjects.

- The process of selection of geo-objects consists in the selection of specific geo-objects that are deemed expedient for integration when creating thematic layers of electronic maps (road signs, traffic lights, road barriers, street-road network, etc.) and integrated types of objects (gas stations, level crossings integrated road traffic management scheme).

- Simplification is included in the standardization method, aimed at eliminating unjustified duplication of the diversity of geo-objects of the same name by simply reducing the number of their varieties to the required (lighting devices, power lines, gas pipelines, etc.).

- Typing of geo-objects based on the creation of standard geo-objects, integrated schemes, technological rules, complex forms of documentation (typical schemes of traffic management around educational institutions; in the production of road works on the road network, etc.).

- Optimization of visualization and dislocation of geoobjects is to find the optimal main parameters, as well as the values of other indicators of quality and efficiency (building the optimal route, the dislocation of signs of priority at the intersection, route, transport network). The optimization methods for visualization and deployment of geo-objects in ITSGIS are based on artificial intelligence methods, expert systems, neural network technologies.

The algorithm of the sequence of steps for the development of the ITSGIS standard is presented in Fig. 3.

\section{Step 1. Organization of the ITSGIS standard development}

The organization of the development of a standard for the visualization and deployment of geo-objects of the ITSGIS intelligent transport geographic information system is carried out in accordance with the "Program for the Development and Revision of Standards". Began with the collection of applications for the development of the standard. Applicants are companies working with ITSGIS, which send applications to the technical committee of IntelTrans. Based on applications, an annual standardization plan is formed.

\section{Step 2. Identification of ITSGIS standard development departments and executives.}

The activity on the development and implementation of a standard begins with the publication by the director of an order on the establishment of a technical committee and the approval of a plan for developing a standard. Organized by a technical committee on standardization. At this stage, the technical committee seeks to more specifically designate developers and executives, from whom it is advisable to obtain a draft standard on the visualization and deployment of geo-objects.
The technical committee includes specialists with various information about the object of standardization and various experience.

Step 3. Establishing the terms of development - the beginning and the end of the work.

Step 4. Study and analysis of the issue status by geoobjects

Establishing the type of standard and its content. Development of the draft standard: the first edition.

The collection of information about the objects of various subject areas implemented on the thematic layers of ITSGIS is aimed at defining the regulatory requirements for a standardized geoobject, improving the quality of the development of the thematic layer.

The composition of the information to be collected is approved by the technical committee and includes:

- regulatory requirements for a standardized object;

- draft standards for analogous geo-objects of ITSGIS analogs;

- results of studies conducted to identify the problems of this geoobject;

- quality indicators applicable to a standardized geoobject, and methods of their visualization.

After collecting the information, the technical committee analyzes the collected information and highlights the data applicable for the development of the draft standard.

\section{Step 5. Discussion of the project in the interested departments and outside organizations.}

Research of information about geo-objects is carried out to confirm their applicability and to obtain the missing information needed to solve the completeness of the description of geo-objects of this thematic layer.

During the study of information about geo-objects, the technical committee determines the objectives for developing the ITSGIS standard:

- ensuring scientific and technical progress in the use of ITSGIS in solving problems of geo-objects dislocation on thematic layers [10];

- increase the competitiveness of products;

- rational use of geo-objects location resources on thematic layers;

- technical and informational compatibility of thematic layers;

- comparability of research results;

- interchangeability of geo-objects of thematic layer.

Step 6. On the draft standard received comments and suggestions?

By decision of the management, the draft standard ITSGIS was sent for examination to the competent organizations. In the course of drawing up a standard for the deployment and visualization of geo-objects, a discussion of 
the developed standard was held. If necessary, the elimination of comments was performed (Step 7).

\section{Step 7. Elimination of comments received during the} discussion.

\section{Step 8. Development of the final version of the draft} standard.

The standard was developed taking into account Russian standards for general technical geographic information systems, as well as other national standards applicable to products manufactured in the environment.

The procedure for the development, approval, accounting, amendment and cancellation of the ITSGIS standard is established subject to the provisions of the Federal Law "On Technical Regulation".

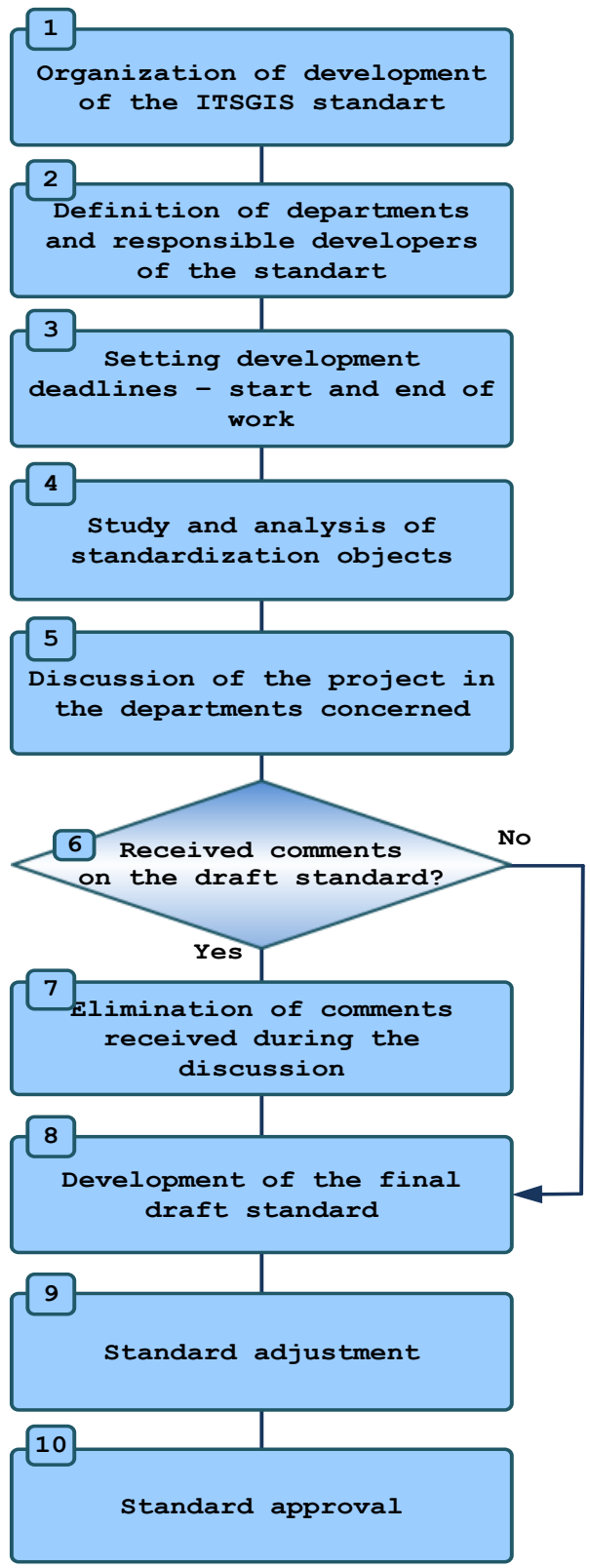

Fig. 3. Algorithm of standardization
Step 9. Adjustment of the standard.

Cancellation of the existing standard can be carried out with its replacement with a new standard or without replacement. The ITSGIS standard is updated or abolished by the decision of the ITSGIS developer company, which has adopted the standard. Standards for ITSGIS are revised to introduce new geo-objects research results or visualization achievements. The abolition of this category of regulatory documents is associated with obsolete geo-objects of standardization.

\section{Step 10. Adjustment of the standard.}

The technical committee has prepared a draft standard and an explanatory note to it. The explanatory note to the draft standard ITSGIS shows:

- the basis for the development of a standard based on the ITSGIS Standard Provision;

- brief description of geo-objects of thematic standardization layers;

- information on the compliance of the draft standard with the legislation of the Russian Federation, international, regional standards, rules, norms and recommendations for standardization;

- information on the patent purity of the draft standard;

- information on the relationship of the draft standard with other normative documents on standardization and proposals for their revision, amendment or repeal;

- information on approval;

- information sources.

Before the standard was approved, it was examined for compliance with the laws of the Russian Federation, current technical regulations, and national standards.

The rules for the examination and monitoring of the draft standard ITSGIS are included in the standard on the general procedure for developing standards for various thematic layers. IntelTrans has established a procedure for the examination of draft standards of various thematic ITSGIS layers with the involvement of specialists from the technical committee for standardization. The standards of geo-objects deployed and visualized on thematic layers of ITSGIS are approved by the personal signature of the General Director of IntelTrans $[14,15]$.

After the completion of the described steps of developing the ITSGIS standard in IntelTrans, its implementation is carried out.

After the draft standard has been developed and recommended by the technical committee for adoption, it is sent to the national standardization body (Rosstandart) for approval and registration in the national register of current RF standards, where it is assigned the appropriate designation. From the moment of registration in the state register of the Russian Federation, the standard becomes an official document. Further, during the term of validity, the standard can be updated. In this case, changes may be made, it can be revised, replaced, or cancelled. The results of the revision are presented by publishing a new edition of the regulatory document [16]. 


\section{REFERENCES}

[1] Mikheeva T.I Patterny proektirovaniya sloghnoorganizovannyh system / T.I. Mikheeva, S.V. Mikheev, O.K. Golovnin, O.N Saprykin. - Samara : Inteltrans, 2015. - 216 p

[2] Elizarov V.V. Standart dislokacii i visualizacii geoobjectov na electronnoy karte v srede ITSGIS / Mikheeva T.I., Golovnin O.K., Elizarov V.V. // Sovremennye problemy bezopasnosti ghiznedeyatelnosti: intellectualnye transportnye systemy i situacionnye centry, 2018. - Part I. - P. 261.

[3] Lific I.M. Standartizaciya, metrologiya i sertificaciya: Uchebnik.- 2-e izd., pererab. i dop.- M.: Yurayt-Izdat, 2003.- 318 p.

[4] Aronov I.Z., Versan V.G. Prakticheskie rekomendacii po razrabotke technicheskih reglamentov na produkciyu // Standarty I kachestvo. 2004. №11. - P. 72-76.

[5] Mikheeva T.I. Parametrizatciya upravlyauschih objectov urbanizirovannoy territorii / S.V. Mikheev, O.K. Golovnin // Izvestiya Samarskovo nauchnovo Centra Rossiyskoy akademii nauk. - 2015. T. 17, № 2 (5). - P. 1058-1062.

[6] Mikheeva, T.I. Instrumentalnaya sreda dlya proektirovaniya objektov intellectualnoy transportnoy systemy // Vestnik Samarskovo gos. techn. un-ta. Seriya «Tekhnicheskie nauki» №40. Samara: SamGTU, 2006. P.96-103.

[7] Mikheeva T.I. Patternovoe proektirovaniye intellektualnyh transportnyh system [Electrony resurs]/T.I. Mikheeva, O.K. Golovnin, A.A. Fedosseev//Sovremennye problem nauki I obrasovaniya. - 2012. - № 6; URL: http://www.scienceeducation.ru/106-7967.
[8] Fedoseev A.A., Golovnin O.K., Mikheev S.V. Sintez tematicheskovo sloya objektov transprotnoy seti// Izvestiya Samarskovo Nauchnogo centra Rossiyskoy akademii nauk. - 2016. - T. 18, № 4 (4). - P. 839843.

[9] Mikheeva T. I. Intellektualnaya transportnaya geoinformacionnaya systema ITSGIS. Plaginy / T.I. Mikheeva, S.V. Mikheev i dr. Samara : Inteltrans, 2016. - T.2. - 217 p.

[10] Mikheeva, T.I. Intellektualnya transportnaya systema. Dislokatsiya doroghnyh znakov / // Vestnik Samarskovo gos. techn. un-ta. Seriya «Tekhnicheskie nauki» №32. Samara: SamGTU, 2005. P.53-63

[11] G. Eason, B. Noble, and I. N. Sneddon, "On certain integrals of Lipschitz-Hankel type involving products of Bessel functions," Phil. Trans. Roy. Soc. London, vol. A247, pp. 529-551, April 1955. (references)

[12] Garcia, E., Casbeer, D., 2017. Coordinated Threat Assignments and Mission Management of Unmanned Aerial Vehicles. In Cooperative Control of Multi-Agent // Systems: Theory and Applications. P. 141.

[13] Golovnin O.K. Intelligent geographic information platform for transport process analysis / O. Golovnin, A. Fedoseev, T. Mikheeva // CEUR Workshop Proceedings, 2017. - Vol. 1901. - P. 78-85. - DOI : 10.18287/1613-0073-2017-1901-78-85.

[14] Golovnin O.K., Mikheeva T.I. Attribute-driven network-centric urban transport process control system modelling // Journal of Physics: Conference Series. - 2018. - Vol. 1096. Issue 1.

[15] Ostroglazov N., Golovnin O., Mikheeva T. System analysis and processing of transport infrastructure information // CEUR Workshop Proceedings. — 2018. - Vol. 2298. 